\title{
Aerosciences, Aero-Propulsion and Flight Mechanics Technology Development for NASA's Next Generation Launch Technology program
}

\author{
Charles E. Cockrell, Jr. \\ NASA Langley Research Center, Hampton, VA
}

\begin{abstract}
The Next Generation Launch Technology (NGLT) program, Vehicle Systems Research and Technology (VSR\&T) project is pursuing technology advancements in aerothermodynamics, aeropropulsion and flight mechanics to enable development of future reusable launch vehicle (RLV) systems. The current design trade space includes rocket-propelled, hypersonic airbreathing and hybrid systems in two-stage and single-stage configurations. Aerothermodynamics technologies include experimental and computational databases to evaluate stage separation of two-stage vehicles as well as computational and trajectory simulation tools for this problem. Additionally, advancements in high-fidelity computational tools and measurement techniques are being pursued along with the study of flow physics phenomena, such as boundary-layer transition. Aero-propulsion technology development includes scramjet flowpath development and integration, with a current emphasis on hypervelocity (Mach 10 and above) operation, as well as the study of aero-propulsive interactions and the impact on overall vehicle performance. Flight mechanics technology development is focused on advanced guidance, navigation and control (GN\&C) algorithms and adaptive flight control systems for both rocketpropelled and airbreathing vehicles.
\end{abstract}

\section{Introduction}

The United States National Aeronautics and Space Administration (NASA) has established the Next Generation Launch technology program (NGLT) to develop technologies for reusable launch vehicles (RLVS) and achieve significant improvements in safety, reliability and cost effectiveness for space access. ${ }^{1}$ The NGLT program is one element of NASA's Integrated Space Transportation Plan (ISTP), which includes the Space Shuttle and Orbital Space Plane (OSP) development. The NGLT research and technology projects encompass propulsion, vehicle systems, ground demonstrations and flight demonstrations. This program provides balanced technology development to address a range of near, mid and far-term launch requirements.

\footnotetext{
* Aerosciences Manager, NGLT Vehicle Systems R\&T Project Office, NASA Langley Research Center. Senior Member AIAA.
}

Technology development is driven by a suite of reference architecture concepts representative of projected launch requirements. These concepts may generally be categorized by the number of stages and the primary propulsion system utilized. While two-stage concepts are judged to be more viable for near-term applications, single stage concepts remain an option for long-term system development. Propulsion systems options can generally be categorized as rocket, airbreathing and hybrid. Further, airbreathing systems may consist of highspeed turbine, dual-mode scramjet and combinedcycle operation. Hypersonic airbreathing propulsion offers potential performance advantages over conventional rocket propulsion, but requires a greater degree of technology advancement. Figure 1 shows examples of the current reference architecture suite.

The NGLT Vehicle Systems Research and Technology (VSR\&T) Project includes airframe structures and materials, aerosciences, vehicle subsystems and spaceport and range technologies. ${ }^{2}$ Additionally, flight demonstration activities provide a flight validation component for concepts, design methods and ground testing techniques.

The objective of the aerosciences subproject is to develop technologies that provide enhanced aero-propulsive performance, stability and control, and maneuverability of RLV systems in atmospheric flight. Enhanced performance margin leads to increased safety and reliability. Examples include configuration-specific design concepts to enhance aerothermodynamic and aero-propulsive performance, active flow control, high-fidelity analysis and design tools, and advanced adaptive guidance, navigation and control algorithms. Additionally, methods, test techniques and highfidelity experimental and computational databases are being developed to enable complete assessments of vehicle performance and stability and control through representative flight profiles.

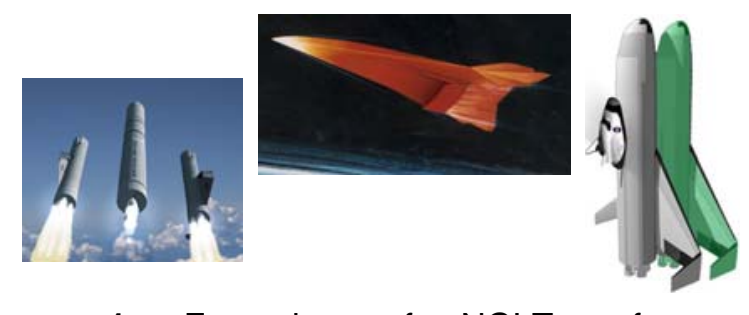

Figure 1. Examples of NGLT reference architecture trade space. 
These assessments include data for aerodynamic forces and moments, global surface aeroheating, tipto-tail flowpath fluid dynamics and adaptive flight control system performance.

Efforts in the aerosciences subproject are grouped into three elements: aerothermodynamics, aero-propulsion and flight mechanics. An overview of each of these elements and their contribution to NGLT program goals and objectives is described herein.

\section{Aerothermodynamics}

Aerothermodynamics is a blend of aerodynamics, aeroheating and fluid dynamics. The blending of these disciplines addresses aspects of vehicle aerodynamic performance, stability and control, and survivability throughout mission trajectories for RLV configurations. Aerothermodynamics assessments must model a wide range of speed regimes and flow physics from takeoff, through ascent to orbital insertion, re-entry, approach and landing. Figure 2 summarizes the various challenges in each flow regime. Each speed regime is characterized by different flow physics and flow chemistry modeling requirements.

\section{Configuration Aerothermodynamics}

Configuration-specific aerothermodynamic assessments are conducted to provide high-fidelity computational and experimental databases to determine vehicle performance. These data are used to enhance the fidelity level of systems concept studies and to investigate potential design concepts or technologies that may lead to performance enhancements.

A high-priority technology shortfall concerns the aerodynamic and aeroheating characteristics during stage separation and abort for two-stage vehicles. A representative TSTO rocket-propelled configuration, referred to as the Langley Glideback Booster (LGBB), is depicted in figure 3. ${ }^{3}$ Test entries have been conducted with this configuration at supersonic (Mach 2.4-3.6), transonic and hypersonic (Mach 6) speeds in various facilities to assemble a database of proximity aerodynamic characteristics for the two bodies. An additional entry will be conducted at Mach 10 ground test conditions. Additionally, an investigation of proximity aeroheating test techniques and characteristics is underway with a pending test entry at Mach 6 conditions. Significant challenges exist in developing the capability to measure three-dimensional surface

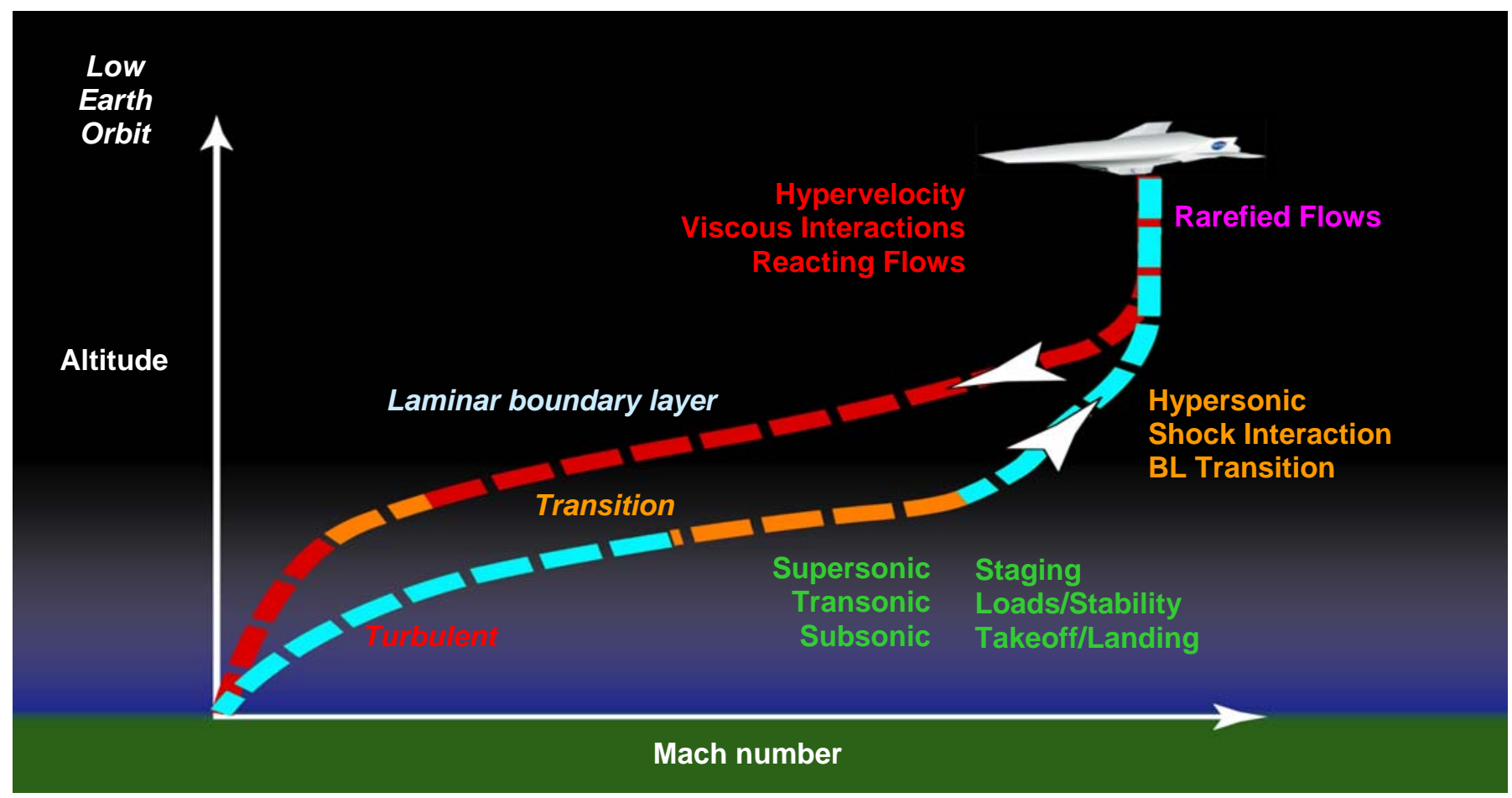

Figure 2. Aerothermodynamic flow physics challenges through ascent and re-entry trajectories. 


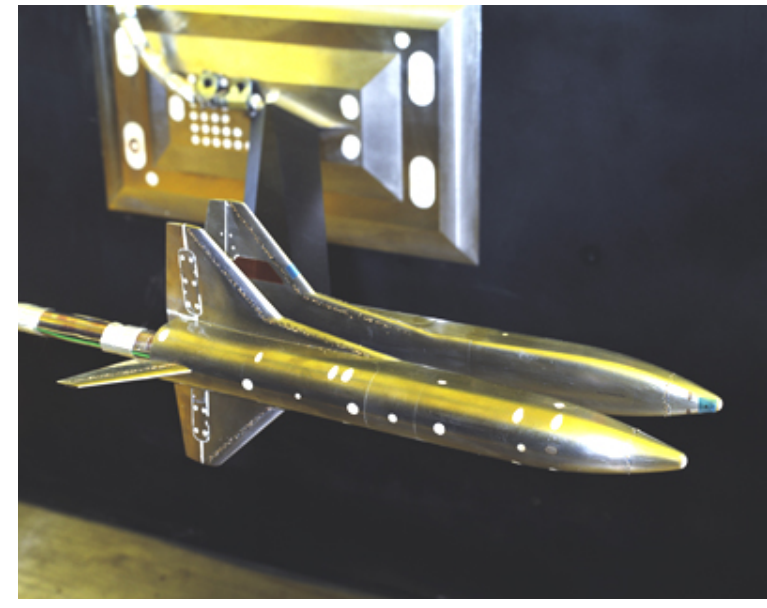

Figure 3. Langley Glideback Booster (LGBB) TSTO configuration.

heating data with two bodies in proximity. These data may be critical to understanding localized heating due to shock interactions or stagnation regions as well as perturbations in aerodynamic forces and moments due to the flow structure during the separation sequence. The complete database will address a wide range of nominal separation and abort scenarios through a representative ascent trajectory.

As a companion effort to the experimental stage separation work, development of computational fluid dynamics (CFD) and engineering analysis tools to simulate stage separation are being pursued. A Chimera-scheme (overset structuredgrid), Navier-Stokes CFD code, OVERFLOW, is the focus of the CFD development. This tool was previously applied to analyze separation of the X43A research vehicle from the booster vehicle. ${ }^{4}$ Code capabilities have since been extended to include a 6-degree-of-freedom (6-DOF) timedependent dynamic simulation capability. Validation of this capability is being accomplished through application to the LGBB and comparisons with the extensive experimental data sets. Figure 4 shows predictions of symmetry plane pressure contours at Mach 3 conditions of the LGBB, obtained with OVERFLOW. An engineering tool is also being developed which incorporates a separation simulation capability into an existing trajectory simulation tool developed for RLV vehicle analyses. When completed, the tool will provide an end-to-end trajectory simulation including separation and abort sequences. The separation simulation tool was also developed and applied to the X-43A separation analysis. ${ }^{5}$

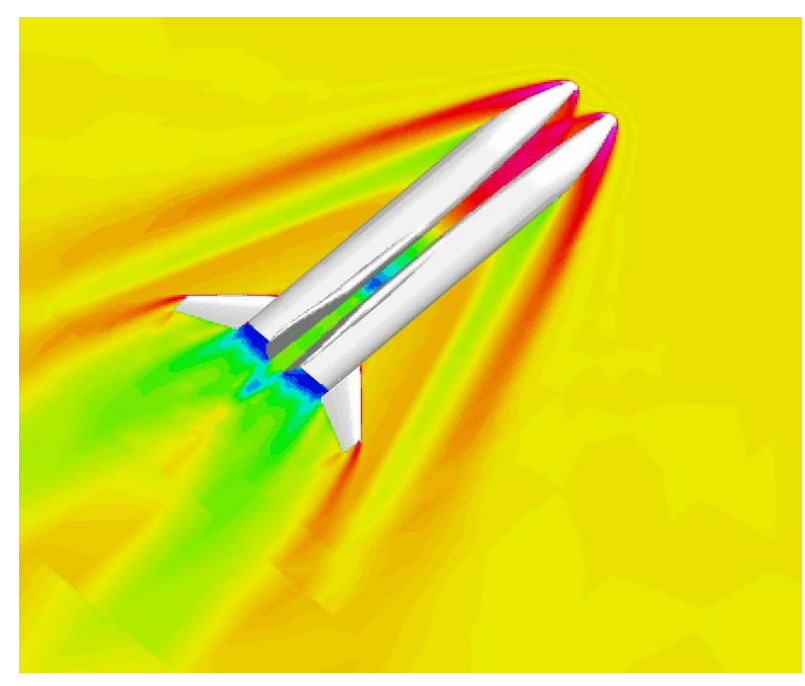

Figure 4. OVERFLOW solution of the LGBB at Mach 3 freestream conditions.

Future work in stage separation aerothermodynamics will focus on vehicle concepts which involve hypersonic airbreathing and combined-cycle propulsion. The separation of liftingbody concepts at hypersonic Mach numbers and high dynamic pressures may introduce a different, more complex, set of aerothermodynamic challenges, including mode transition and propulsion-airframe interactions not previously considered.

\section{Flight Environment Definition}

Continued advancements of high-fidelity computational methods are being pursued to improve uncertainties in aerothermodynamic predictions in conceptual design cycles and preflight assessments. The creation of surface and volume meshes to resolve complex vehicle surface features and provide sufficient resolution to predict surface and flow field quantities is a long-lead item for structured-grid CFD applications. Unstructured grid applications offer the potential to reduce cycle times for high-fidelity analyses, making it feasible to incorporate these methods earlier in the conceptual design process and to make high-fidelity computations possible in rapid configuration assessments. The high-energy flow solver synthesis (HEFSS) code is an unstructured computational tool for viscous, high-temperature, chemically-reacting flows. ${ }^{6}$ This tool combines algorithms and physical models from benchmark solvers used for aerothermodynamic and propulsion flowpath analyses into an existing unstructured-grid, perfectgas CFD code. ${ }^{7-10}$ Mesh generation capabilities and solutions of simplified hypersonic flows have been 
demonstrated and applications to more complex RLV reference configurations are underway. ${ }^{11}$ Figure 5 shows a solution on a blunt cylinder with comparisons to a benchmark structured-grid calculation.

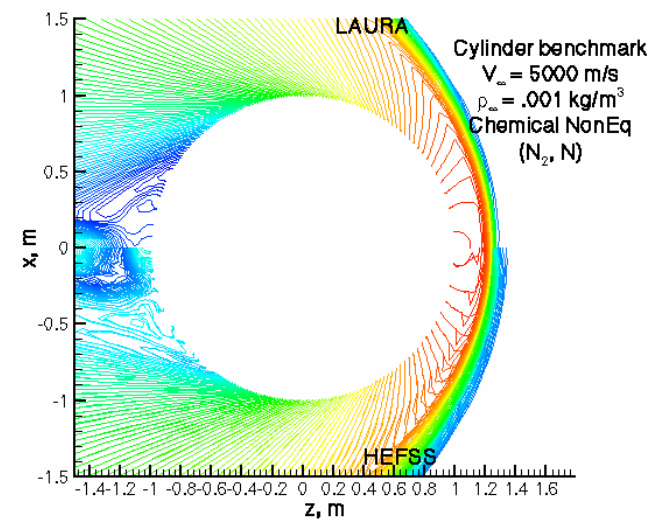

Figure 5. Benchmark solution with HEFSS compared to structured-grid solution.

Advancements in measurement and diagnostic capabilities are also being pursued. Measurement needs include aerodynamic, surface aeroheating and fluid dynamics. These requirements are summarized in table 1 . The design of future RLV systems will require improvements in the uncertainty of aerodynamic and surface aeroheating ground test measurements to characterize pressure and heating loads. Additionally, vehicle development and validation of advanced design tools require off-body fluid dynamic measurements to characterize flow field features.

\section{Characterization of proximity aerodynamics during stage separation requires precise measurement of model orientation and forces and moments. The use of inertial measurement devices in ground test facilities may introduce uncertainties in proximity force and moment measurements. The use of optical measurement devices has been}

demonstrated for various applications. ${ }^{12}$ Application to optical angle of attack measurements in hypersonic ground test facilities will be demonstrated in the near term. Global surface pressure measurements are also needed to fully characterize aerodynamic loads. Pressure sensitive paints (PSP) have been used to successfully measure global quantitative surface pressures at low speeds, but temperature sensitivity is a source of error in these formulations. ${ }^{13}$ Work is progressing to demonstrate the functionality of high-temperature pressure sensitive coatings for hypersonic test applications.

The design of advanced thermal protection systems (TPS) for RLV configurations is dependent on sufficient resolution of surface heating loads. Surface heating measurements also provide information on flow phenomena, such as boundarylayer transition, flow separation and localized shock impingement locations. Infrared imaging has been applied to obtain quantitative measurements on hypersonic wind tunnel models. ${ }^{14}$ The application of high-definition cameras to provide high-resolution three-dimensional surface heating data is being pursued. The application of phosphor thermography technique has also been applied to various hypersonic configurations. ${ }^{15}$ Work is continuing to extend the capabilities of this technique by extending temperature ranges, calibration of software improvements to improve uncertainties for quantitative heating measurements and the development of tools for rapid mapping of heating images to three-dimensional geometries. Figure 6 shows an example of quantitative surface heating measurements obtained using this technique. Areas of high surface heating, including localized regions, are visible.

Flow field fluid dynamic measurements include velocity, temperature, pressure and species. Because probe measurements are not feasible in hypersonic flows due to the flow disturbances that

\begin{tabular}{|l|l|l|}
\hline Category & Measurement Need & Technologies Pursued \\
\hline Aerodynamic & Angle of attack and sideslip. & $\begin{array}{l}\text { Optical attitude measurements in hypersonic test } \\
\text { environments. }\end{array}$ \\
\hline Aeroheating & Surface pressures. & $\begin{array}{l}\text { Gigh-temperature pressure sensitive coatings } \\
\text { (PSC). }\end{array}$ \\
\hline and heat transfer measurements. & Infrared thermography. \\
\hline $\begin{array}{l}\text { Fluid } \\
\text { Dynamic }\end{array}$ & $\begin{array}{l}\text { Flow field velocity, pressure, } \\
\text { temperature and species } \\
\text { measurements. }\end{array}$ & $\begin{array}{l}\text { Phosphor thermography. } \\
\text { applications. (PLIF velocimetry, thermometry). }\end{array}$ \\
\hline
\end{tabular}

Table 1. Summary of aerothermodynamic measurement needs and technologies. 
they induce and high-temperature environments, the focus is on non-intrusive, laser-based, diagnostic methods. Planar laser-induced fluorescence (PLIF) is a technique that has been demonstrated for a wide range of velocimetry measurements. ${ }^{16}$ The application of PLIF with iodine and nitric oxide (NO) seeding will be demonstrated for flow field measurements on a relevant reference configuration at hypersonic test conditions to obtain velocity measurements and, eventually, temperature, density and species measurements. A portable NO PLIF system was recently installed in the NASA-Langley 15-Inch Mach 6 wind tunnel. The system is designed to inject NO through model pressure ports and image fluorescence through optical access to the test section. Future areas of research will also include measurements of velocity components in the proximity of simulated powered exhaust plumes for airbreathing configurations.

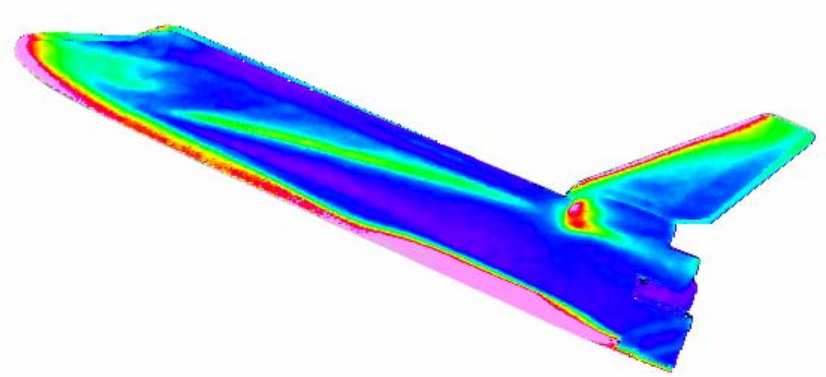

Figure 6. Application of phosphor thermography for quantitative surface heating measurements.

\section{Flow Physics and Control}

Investigation of various aspects of flow physics phenomena are being conducted as a basis to provide improved physical modeling capabilities and to investigate mechanisms to exploit or control local flow fields to provide enhanced performance. Boundary-layer transition modeling and control in the hypersonic speed regime is one such area of research. The ability to predict transition accurately impacts surface heating loads and thermal protection system (TPS) design and sizing. ${ }^{17}$ Additionally, the impact with respect to airbreathing vehicles extends to engine operability and performance as well as aerodynamic drag. Turbulent flow is desirable in the inlet to prevent boundary layer separation in the presence of adverse pressure gradients, but laminar flow is desired along the forebody and leeward external surfaces. The ability of airbreathing systems to achieve positive net thrust is dependent on a small difference between large thrust and drag components at high Mach numbers. Therefore, large uncertainties in transition location could result in increased drag and decreased performance margin. Systems studies include trades to understand the impact of transition, surface heating predictions and turbulent drag on vehicle performance and weights.

Efforts to improve transition prediction models include the application of linear stability theory to hypersonic transition, examination of data from the Pegasus flight experiment ${ }^{18}$ and investigations of direct simulation Monte Carlo (DSMC) approaches to understand physical mechanisms applicable to transition. ${ }^{19}$ Figure 7 illustrates a simulation of laminar flow breakdown using DSMC. Hypersonic flight demonstrator vehicles may require forced transition mechanisms to induce turbulent flow along the forebody surface upstream of the inlet for engine performance and operability. The X-43A program investigated the effectiveness of forced transition via intrusive devices on the forebody surface. ${ }^{20}$ For systems that must operate over a wide Mach number range, it may be desireable to have "transition on demand" capability. This approach has been demonstrated at Mach 6 and Mach 10 conditions on a representative $\mathrm{X}-43 \mathrm{~A}$ forebody through the use of mass injection. Future studies may involve application of mass injection for boundary layer control to improve control surface effectiveness and the use of passive porosity for hypersonic laminar flow control. ${ }^{21}$

\section{Flight Validation}

$$
\begin{gathered}
\text { Validation via flight is an important } \\
\text { component of aerosciences technology }
\end{gathered}
$$

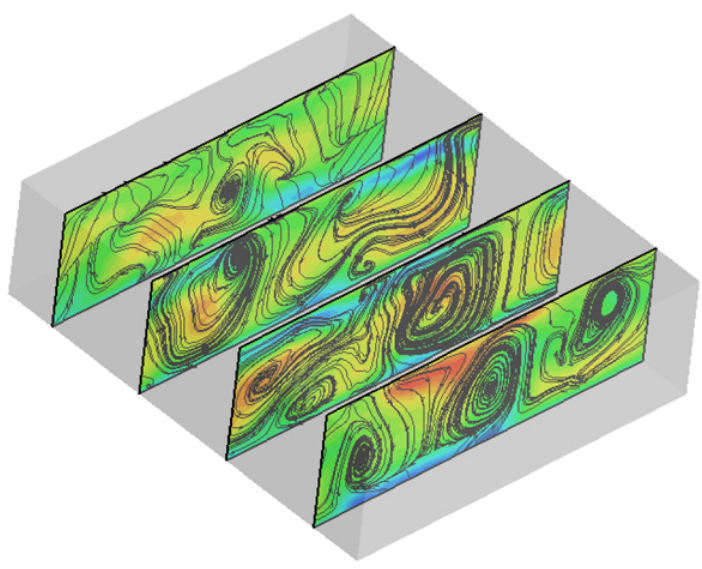

Figure 7. Simulation of laminar flow breakdown using DSMC. 
development. The Vehicle Systems R\&T project is pursuing approaches to develop flight demonstrator testbeds to demonstrate technologies in flight and obtain relevant data to validate analytic tools, design approaches and ground test techniques. These flight tests will generate data directly applicable to validation of aerothermodynamic flow phenomena, including boundary-layer transition, flow separation and reattachment and shock-boundary layer interactions. In addition, the re-entry flight testbed may demonstrate novel flight sensor approaches to obtain surface aeroheating data.

\section{Aero-Propulsion}

Airbreathing and combined-cycle propulsion systems are candidates for mid and far-term RLV applications. Two-stage and single-stage-to-orbit (SSTO) systems that utilize dual-mode scramjet propulsion, integrated with turbine and/or rocket systems are part of the NGLT design trade space. These vehicles are characterized by a high degree of interaction between the airframe and propulsion flowpath. Vehicle performance, stability and control cannot be de-coupled from propulsion performance, due to shared surfaces and flow field interactions, as depicted in figure 8. Therefore, consideration of integrated vehicle aero-propulsive performance must start with design and analysis of the tip-to-tail propulsion flowpath, including the internal flow physics.

\section{$\underline{\text { Scramjet Flowpath Development and Integration }}$}

Research and technology development in airframe-integrated scramjet propulsion is closely

\section{Forebody Shaping, Shock Structure and Boundary-Layer State Impacts Engine Mass Capture, Combustion Efficiency}

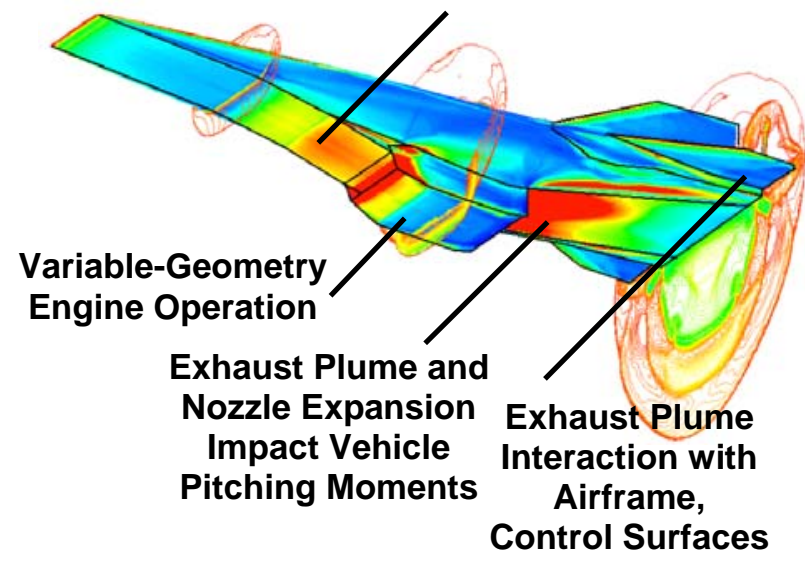

Figure 8. Propulsion-Airframe Integration considerations for hypersonic vehicles. integrated with NGLT hypersonic flight demonstrator projects. ${ }^{22}$ NASA initiated the Hyper-X (X-43) flight research project in 1995 to demonstrate the in-flight performance of a hydrogen-fueled, airframeintegrated scramjet at flight Mach numbers of 5, 7, and $10 .^{23}$ The project was subsequently redirected to focus on Mach 7 and 10 flight tests, with ground engine research continuing at Mach 5. The X-43C project is a joint NASA-Air Force project to achieve a flight demonstration of the USAF HyTech engine, a hydrocarbon-fueled dual-mode scramjet. ${ }^{24}$ Similar to the $\mathrm{X}-43 \mathrm{~A}$, this mission is accomplished by boosting the research vehicle to the flight test altitude and condition via a solid-rocket booster which is airlaunched from a B-52 aircraft. Whereas the X-43A is designed to achieve only a few seconds of powered flight at a single point design condition with heat-sink hardware, the $\mathrm{X}-43 \mathrm{C}$ vehicle is designed to fly an accelerating trajectory from Mach 5 to 7 , demonstrating ramjet-scramjet mode transition. Additionally, the X-43C engine utilizes active regenerative fuel cooling, which will provide a validation of the heat exchanger design and the endothermic cooling capacity of liquid JP-7 fuel. The feasibility of a reusable combined-cycle flight demonstrator (RCCFD) is also being investigated. The RCCFD would demonstrate combined turbine and scramjet operation up to Mach 7.

A significant technology shortfall exists in providing high-fidelity databases to validate scramjet performance at hypervelocity (Mach 10 and above) speeds. As indicated in figure 9, the specific impulse of the scramjet cycle decreases as Mach number increases. Heat release due to combustion is inversely proportional to the square of the freestream Mach number. At Mach 15, the combustion energy is approximately less than 25percent of the free stream kinetic energy, accounting for flow field losses. ${ }^{25}$ At these Mach numbers, small changes in effective specific impulse can cause significant changes in vehicle take-off gross weights, thus impacting the ability of the system to meet mission performance requirements. ${ }^{26}$ This represents a practical upper limit for efficient scramjet engine operation. A further understanding of the fundamental physical processes that govern engine performance in the hypervelocity speed range is required in order to optimize flowpath lines for efficient operation and determine practical operational limits.

Tests have been conducted most recently on a scramjet flowpath model, representative of the Mach 10 X-43A scramjet flowpath lines, at Mach 15 conditions in the NASA Hypersonic Pulse 


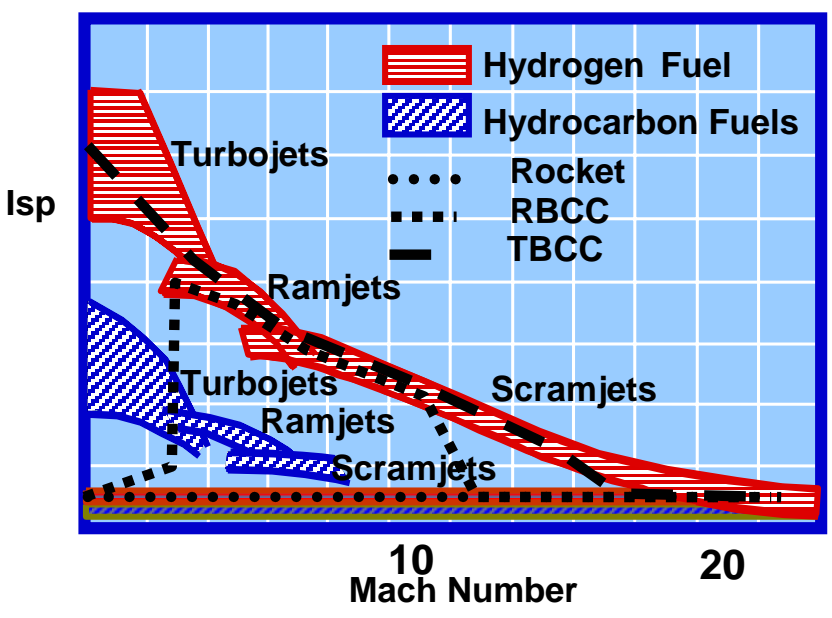

Figure 9. Airbreathing Propulsion Performance.

(HYPULSE) facility. ${ }^{27}$ This configuration is depicted in figure 10. The HYPULSE facility may be operated in either reflected shock tunnel (RST) or shock expansion tunnel (SET) conditions. ${ }^{28}$ Design of a hypervelocity scramjet model (HySM) is underway to obtain a ground test data base for Mach 12-15 scramjet performance. Additionally, definition and calibration of baseline test points for SET operation in the Mach 12-15 range is underway. This includes the design and fabrication of a facility nozzle suitable for scramjet flowpath tests, and efforts to optimize and calibrate the shock tunnel exit flow conditions for these flight Mach numbers. These efforts will build a comprehensive hypervelocity performance database to optimize high-speed flowpath design and refine performance calculations in vehicle studies. Future hypersonic flight demonstrators are planned to obtain flight data for airframe-integrated scramjet operation at hypersonic Mach numbers.

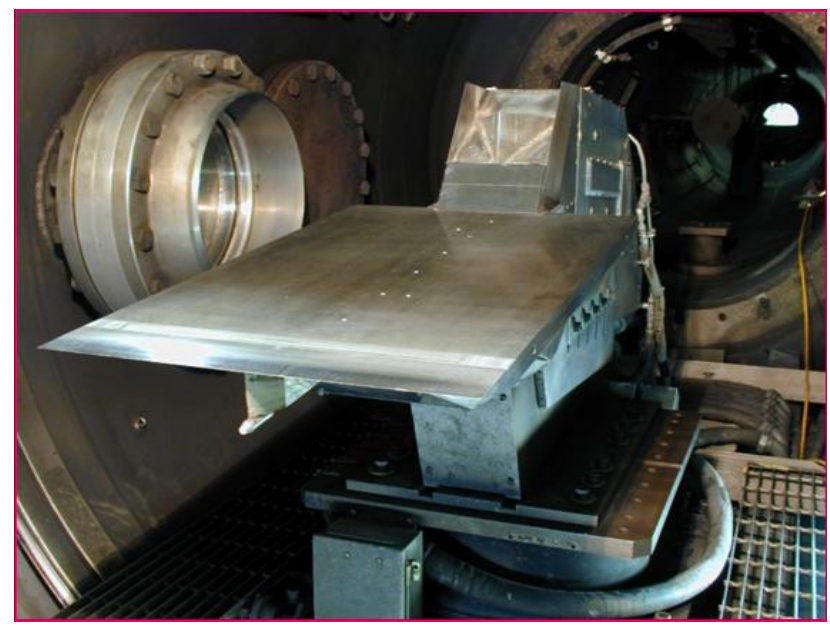

Figure 10. Representative flowpath model installed in NASA Hypersonic Pulse facility.
Dual-mode scramjet engine cycles must function over a wide Mach number range in order to meet mission requirements. Additionally, configurations that utilize airbreathing propulsion include multiple engine cycles and the issue of mode transition must be addressed. One concept is the integration of high-speed turbine engines with dualmode scramjet for the first-stage of a two-stage vehicle or for SSTO vehicles. ${ }^{29}$ Various studies have been conducted to examine the integration of turbine and scramjet flowpaths. A dual-flowpath inlet test article will be tested to investigate the effects on high-speed inlet performance during transition on a representative configuration.

Depending on the Mach number range and specific mission requirements, efficient inlet operation over the applicable flight regime may necessitate variable contraction ratios. Variablegeometry concepts have been examined to provide this required operability. Efficient multi-speed engine operation also requires the development of fueling strategies and engine control mechanisms. A longerterm objective of this program is to conduct a comprehensive test program to investigate parametric performance for Mach 3-8 operation, examine contraction ratio differences, examine performance during mode transitions, and verify closed-loop control algorithms.

\section{Aero-Propulsive Interactions}

Installed vehicle performance is a combination of propulsion system and vehicle aerodynamic performance for airbreathing systems. Assessments of vehicle performance includes simulation of powered effects in analytic modeling and ground testing. Various ground test techniques are used to evaluate the effects of powered operation on tip-to-tail flowpath and vehicle performance, including forebody-inlet test models, partial and full flowpath models with combustion, and the use of air or gas mixtures to simulate powered exhaust plume effects in aerodynamic facilities. $^{30}$

During the National Aero-Space Plane (NASP) program, significant work was done to investigate the use of cold-gas mixtures to simulate powered scramjet exhaust products in ground test facilities. ${ }^{31-33}$ This technique was investigated in the supersonic and hypersonic speed regimes (Mach 410) with powered metric aftbody models to develop the technique and measure external nozzle pressures, exhaust plume impingement on wing surfaces and aftbody forces and moments. Analysis 
to examine the correlation of cold simulant gases to hot combustion products was initiated, but not completed due to the termination of this program. The X-43A flight project undertook a significant ground testing and computational effort to build the pre-flight vehicle database. ${ }^{34,35}$ This effort consisted of un-powered aerothermodynamic testing with powered force and moment increments supplied by CFD predictions. These predictions were verified by full-flowpath force and moment data obtained from the Hyper-X Flight Engine (HXFE) testing in the Langley 8-Ft. HTT, as shown in figure $11 .^{36}$

Efforts are underway to investigate improvements to sub-scale exhaust simulation test techniques. Development of future hypersonic flight demonstrators and operational vehicles will require assessments of aero-propulsive performance over complete flight trajectories. Advancements in ground test data are required to develop capabilities for aero-propulsive database development and multiple conditions within reasonable cycle times. Potential test technique advancements include the application of on-board rocket motors to test fully-metric wind tunnel models and an investigation of continuous hot-gas simulation with comparisons to cold-gas mixture simulation and testing with actual combustion products.

Vehicle systems studies have identified installed transonic performance predictions as having a high degree of uncertainty. Current analytical methods are not sufficient to fully characterize the integrated powered vehicle performance in this speed range. A previous test was conducted in the Langley 16-Foot Transonic Tunnel to measure nozzle/aftbody flow field characteristics and forces and moments on a NASP

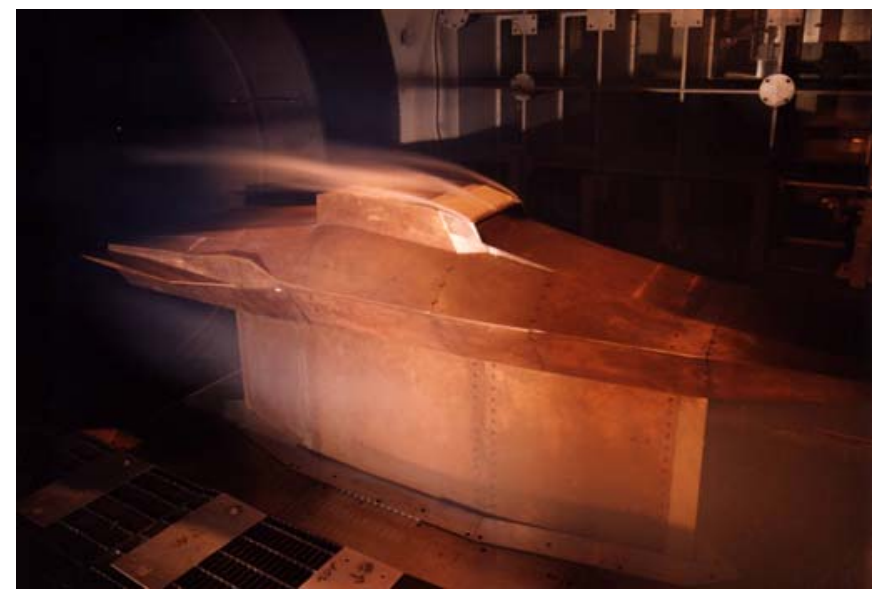

Figure 11 Hyper-X Flight Engine (HXFE) in the Langley 8-Ft. High Temperature Tunnel (HTT). vehicle model. Figure 12 shows a photograph of this configuration installed in the tunnel test section. Comparisons between these test data and CFD predictions provided insight in aftbody flow field structures that influence installed forces and moments. ${ }^{37,38}$ These comparisons suggest that engineering tools are insufficient to fully resolve transonic forces and moments and it is desirable to utilize high-fidelity CFD to fully analyze the problem. Application of the HEFSS unstructured CFD code, described previously, to this problem is being investigated.

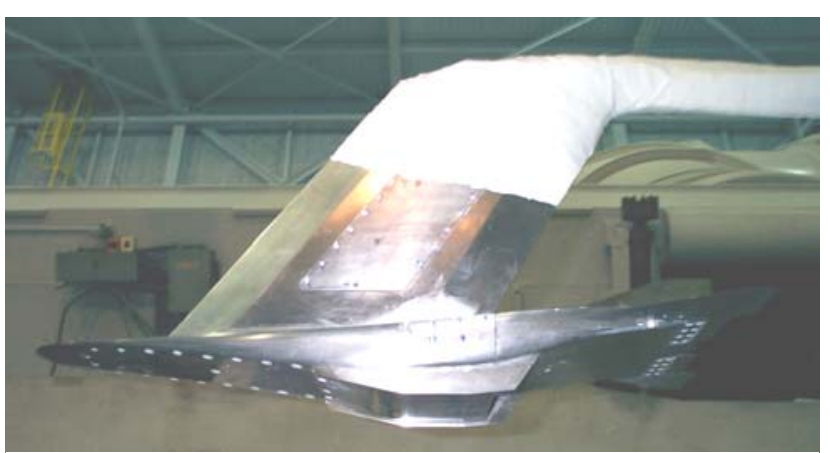

Figure 12. Powered aftbody simulation test

\section{Flight Mechanics}

The technology focus in the flight mechanics element is on the development of advanced adaptive guidance, navigation and control (GN\&C) approaches for RLV configurations. Traditional guidance and control approaches are designed to provide acceptable performance and stability as long as the parameters (mass properties, engine performance, aerodynamics, atmospheric conditions, and flight trajectory) remain within a narrow design envelope. Advanced guidance and control approaches seek to expand the envelope using robust, adaptive algorithms. These approaches enable the development of flight control systems that can adapt to a wide range of trajectory dispersion, failure and abort scenarios, thus providing improvements in safety and reliability for future RLV systems.

Recent work has focused on development and testing of adaptive GN\&C algorithms with specific applications to rocket-propelled configurations. Figure 13 shows a conceptual schematic of an adaptive GN\&C system. ${ }^{39}$ The elements of this system are described as follows.

- The autonomous flight manager is a supervisory control unit that synthesizes inputs from the flight control system, vehicle sensors 
and navigation system to analyze vehicle parameters and determine appropriate actions to adapt to dispersions, failures and abort scenarios.

- Trajectory generation algorithms determine redesigns of the flight profile based on sensed vehicle performance, new flight constraints and current conditions.

- Adaptive guidance algorithms modify attitude commands in response to dynamic flight conditions, off-nominal conditions or trajectory updates.

- Adaptive re-configurable control algorithms determine control torques necessary to maintain vehicle control.

- Control allocation algorithms determine inputs to available control effectors to allow full-use of vehicle control effectiveness in off-nominal conditions.

- $\quad$ System identification algorithms determine the current flight vehicle behavior using sensed data.

Advancements in algorithm approaches have been made for several of these components. Several algorithm approaches were evaluated in high-fidelity simulations that included nominal mission, abort, failure, and aerodynamic and propulsion dispersion scenarios. ${ }^{40}$ Closed-loop ascent guidance and entry guidance with on-board trajectory re-design has been demonstrated in existing simulation platforms. ${ }^{41,42}$ Several robust reconfigurable attitude control algorithms have been matured and evaluated in integrated guidance and control testing. These include a Theta-D algorithm ${ }^{43}$, neural network ${ }^{44}$, trajectory linearization controller $(\mathrm{TLC})^{45}$, and a sliding mode controller. ${ }^{46}$ These approaches significantly reduce the number and controller tuning parameters that must be modeled. Figure 14 illustrates an example of integrated test scores for the SMC algorithm. Results for four failure scenarios are shown, including elevon failures and mis-modeling of lift, drag and pitching moment coefficients. A comparison to performance of the baseline (Shuttle-derived) algorithm is shown in the figure. Several control allocation approaches have been tested in integrated test environments. A modified sequential least squares (MSLS) approach for system identification has achieved TRL-3. The near-term approach will continue to examine selected algorithms for adaptive guidance, attitude control and control allocation. The integrated testing and simulation environment will also include the LGBB database in the future as a representative two-stage-to-orbit vehicle.

In addition to advancements in adaptive GN\&C algorithms, work was performed on adaptive flight control architecture design and simulation tool

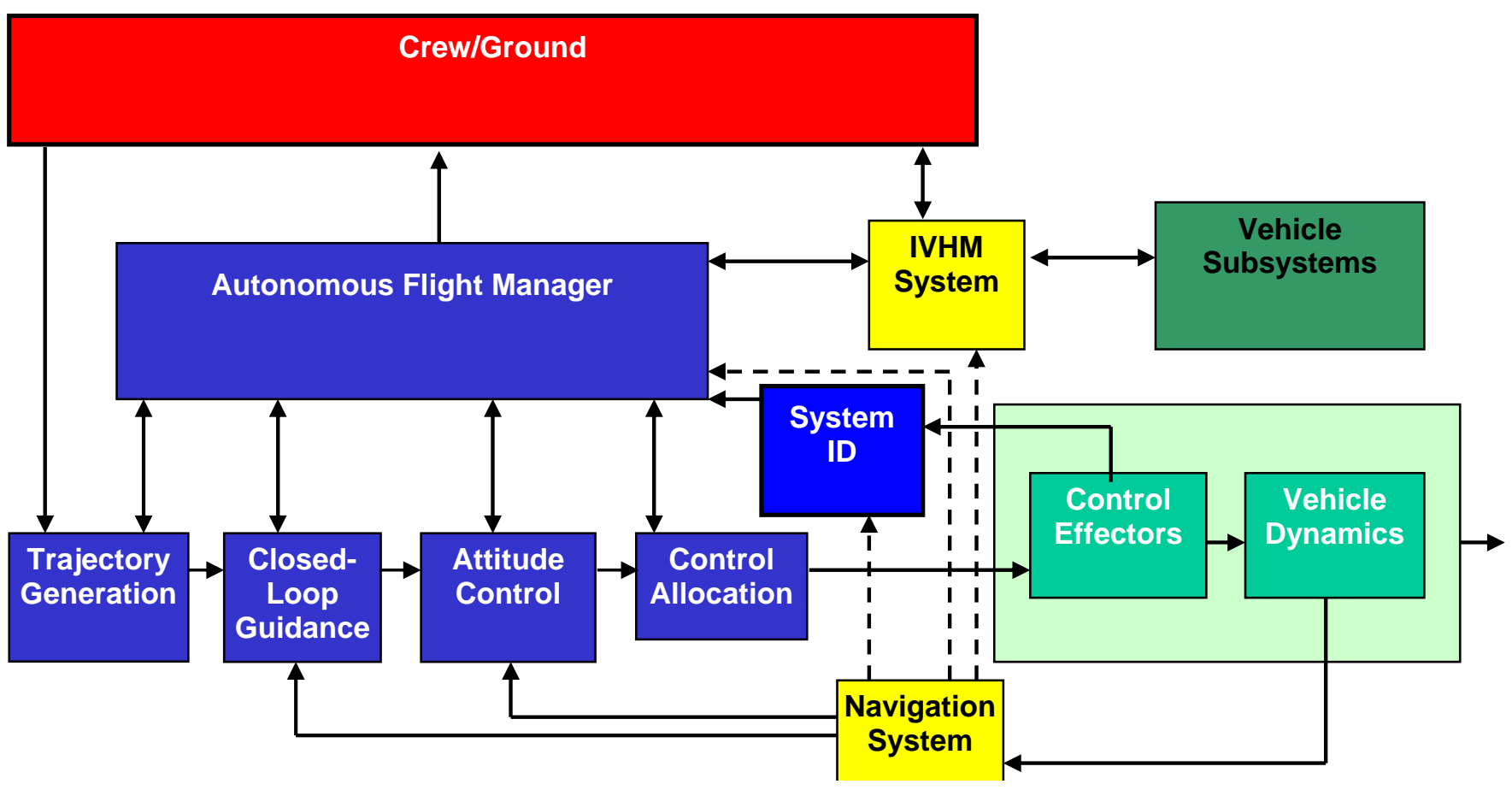

Figure 13. Conceptual design of an advanced adaptive Guidance, Navigation and Control (GN\&C) system. 


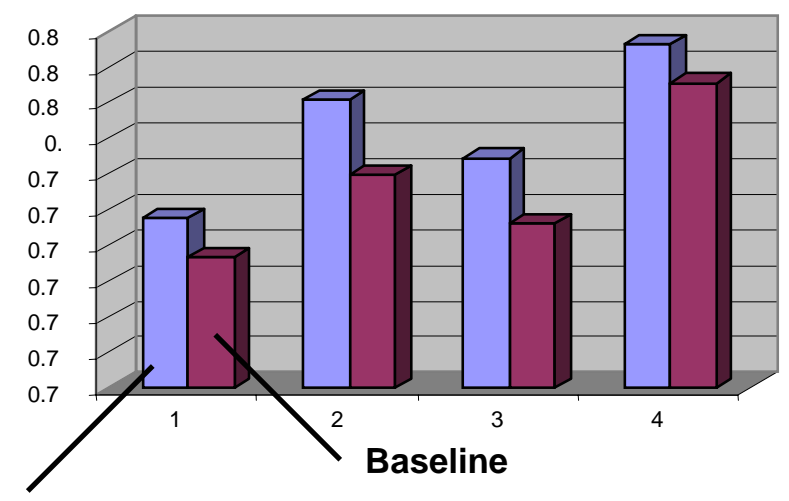

SMC-SMO Algorithm

Figure 14. Comparisons of algorithm test results for SMC-SMO control algorithm.

development. A framework for the autonomous flight manager, or "autocommander" was demonstrated with placeholder algorithms for guidance and control. Autonomous guidance and control adaptation, reconfiguration capability and autonomous abort functionality was demonstrated in simulation test environments. An advanced GN\&C design and simulation tool, known as the Integrated Development and Operations System (IDOS) tool, was formulated in the former Space Launch Initiative (SLI) program. Functionality of several advanced GN\&C algorithms were demonstrated in the IDOS environment. Further development of flight control system architectures and advanced development tools is on hold pending future risk reduction programs for future operational RLV system development.

Hypersonic vehicles have a much wider parameter space for possible trajectory dispersions, failure and abort scenarios. Mode transitions, engine unstarts, flameouts, undesirable module and flowpath interactions must all be considered. Furthermore, due to propulsion-airframe integration considerations, the propulsion and vehicle control systems may be closely coupled. Engine control algorithms are required to control variable contraction ratio schedules and control fuel flow rates to provide required thrust to meet mission objectives, enable mode transitions and to prevent and recover from engine unstart and flameout. The NASP program addressed trajectory design and guidance algorithms. Engine and vehicle control systems for hypersonic vehicles were also investigated in the Hyper-X program and work is proceeding for the current $X-43$ program. ${ }^{47}$ The current R\&T program includes a study of failure and abort scenarios for hypersonic vehicles and conceptual flight control system architecture design.

\section{Summary}

NASA is pursuing a broad range of technologies to enable development of future reusable launch vehicle (RLV) systems. Reference design architectures include two-stage and singlestage-to-orbit vehicles with rocket, airbreathing and hybrid propulsion systems. As part of the Next Generation Launch Technologies (NGLT) program, the Vehicle Systems Research and Technology Project include airframe structures and materials, aerosciences, subsystems, spaceport and range, and technology flight demonstrators. Aerosciences technologies include aerothermodynamics, aeropropulsion and flight mechanics. Technology shortfalls addressed include configuration aerodynamics and aerothermodynamics during stage separation of two-stage vehicles and dualmode scramjet flowpath development and integration for high speed operation. Additionally, advancements in computational tools and methodologies, physics-based models, measurement diagnostics and test techniques are being made. Advanced guidance, navigation and control algorithms are being developed to realize safety and reliability goals for future RLV systems.

\section{Acknowledgements}

The author gratefully acknowledges several team members for their significant contributions to the work presented in this paper and for editorial comments and review. Dr. Ron Merski leads NGLT aerosciences efforts in the NASA-Langley Aerothermodynamics Branch and also leads the surface measurement diagnostics. Kelly Murphy leads the experimental stage separation work and Pieter Buning leads the corresponding computational tool development. Mike Marcolini, Head of the NASA-Langley Advanced Measurements and Optical Sensors Branch, leads the advanced measurement and diagnostic activities. Dr. Clay Rogers leads the hypervelocity flowpath development testing and development. Jack Mulqueen leads the advanced guidance, navigation and control element at NASA-Marshall and John Hanson leads the integrated guidance and control testing efforts.

\section{References}

1. Hueter, Uwe. "NASA's Next Generation Launch Technology Program - Strategy and Plans," Presented at the $54^{\text {th }}$ International Astronautical Conference, October 2003. 
2. Bowles, David E. "Next Generation Launch Technology, Vehicle Systems Research and Technology Project - Framing Future Space Transportation Systems," Presented at the $54^{\text {th }}$ International Astronautical Conference, October 2003.

3. Bordelon, Wayne J.; Frost, Alonzo L.; Reed, Darren K. "Stage Separation Wind Tunnel tests of a Generic Two-Stage-to-Orbit Launch Vehicle," AIAA Paper 2003-4227, Presented at the AIAA Joint Propulsion Conference, July 2003.

4. Buning, Pieter G.; Wong, Tin-Chee; Dilley, Arthur D. and Pao, Jenn L. "Prediction of HyperX Stage Separation Aerodynamics Using CFD," AIAA Paper 2000-4009, Presented at the $18^{\text {th }}$ AIAA Applied Aerodynamics Conference, August 2000.

5. Tartabini, Paul V.; Bose, David M.; McMinn, John D.; Martin, John G. and Strovers, Brian K. "Hyper-X Stage Separation Trajectory Validation Studies," AIAA Paper 2003-5819, Presented at the AIAA Modeling and Simulation Technologies Conference, August 2003.

6. Kleb, William L.; Nielsen, Eric J.; Gnoffo, Peter A.; Park, Michael A. and Wood, William A. "Collaborative Software Development in Support of Fast Adaptive AeroSpace Tools (FAAST)," AIAA Paper 2003-3978, Presented at the AIAA Computational Fluid Dynamics Conference, June 2003.

7. White, Jefferey A. and Morrison, J.H. "A Pseudo-Temporal Multi-Grid Relaxation Scheme for the Parabolized Navier-Stokes Equations," AIAA Paper 99-3360, AIAA $14^{\text {th }}$ Computational Fluid Dynamics Conference, June 1999.

8. Cheatwood, F. M. and Gnoffo, P. User's Manual for the Langley Aerothermodynamic Upwind Relaxation Algorithm (LAURA), NASA TM-4674, 1996.

9. Anderson, W.K. and Bonhous, D.L. "An Implicit Upwind Algorithm for Comuting Turbulent Flow on Unstructured Grids," Computers and Fluids, vol. 23, no. 1, January 1994, pp. 1-21.

10. Anderson, W.K., Rausch, R.D., and Bonhaus, D.L. "Implicit/Multigrid Algorithms for Incompressible Turbulent Flows on Unstructured Grids," Journal of Computational Physics, vol. 128, no. 2, 1996, pp. 391-408.

11. Jones, William T. "GRIDEX - An Integrated Grid Generation Package for CFD," AIAA Paper 2003-4129, Presented at the AIAA $16^{\text {th }}$ Computational Fluid Dynamics Conference, June 2003.

12. Jones, Thomas W. and Hoppe, John C. "Comparison of Angle of Attack Measurements for Wind Tunnel Testing," AIAA Paper 20010559, Presented at the $39^{\text {th }}$ AIAA Aerospace Sciences Meeting, January 2001.

13. Wright, Kenneth D.; Washburn, Anthony E.; Jordan, Jeffrey D.; Leighty, Bradley D.; Watkins, A. Neal; Ingram, JoAnne L.; Oglesby, Donald M.; Fleming, Gary A.; Scott, Michael A.; Balla, R. Jeffrey; Hart, Roger C.; Herring, G.C. and Fletcher, Mark T. "measurement Technology for Use in Active Flow Control," AIAA Paper 20022705, Presented at the $22^{\text {nd }}$ AIAA Aerodynamic Measurement Technology and Ground Testing Conference, June 2002.

14. Daryabeigi, Kamran; Berry, Scott A.; Horvath, Thomas J. and Nowak, Robert J. "Finite Volume Numerical Methods for Aeroheating Rate Calculations from Infrared Thermographic Data," AIAA Paper 2003-3634, Presented at the 36th AIAA Thermophysics Conference, June 2003.

15. Merski, N.R., "Global Aeroheating Wind-Tunnel Measurements Using Improved Two-Color Phosphor Thermography Method," Journal of Spacecraft and Rockets, vol. 36, no.2, 1999, pp. 160-170.

16. Danehy, P.M., O'Byrne, S., Houwing, A.F.P., Fox, J.S., Smith, D.R. Flow-Tagging Velocimetry for Hypersonic Flows Using Fluorescence of Nitric Oxide. AIAA Journal, vol. 41., no.2, February 2003, pp. 263-271.

17. Kimmel, Roger L. "Aspects of Hypersonic Boundary-Layer Transition Control," AIAA Paper 2003-772, Presented at the AIAA $41^{\text {st }}$ Aerosciences Meeting and Exhibit, January 2003.

18. Bertelrud, Arlid; delaTova, Geva; Hamory, Phillip J.; Young, Ronald; Noffz, Gregory K.; Dodson, Michael; Graves, Sharon S.; Diamond, John K.; Barlett, James E.; Noack, Robert; Knobleck, David. Pegasus Wing-Glove Experiments to Document Hypersonic Crossflow Transition: Measurement System and Selected Flight Results. NASA TM 2000-209016, 2000.

19. Liou, William W., Fang, Yichuan, and Bird, Graeme A. "DSMC Simulations of Forced Chaotic Flows," AIAA Paper 2003-3595, Presented at the AIAA $33^{\text {rd }}$ Fluid Dynamics Conference and Exhibit, June 2003.

20. Berry, Scott A.; Auslender, Aaron A.; Dilley, Arthur D. and Calleja, John F. "Hypersonic Boundary-Layer Trip Development for Hyper-X," Journal of Spacecraft and Rockets, vol. 38, no. 6, pp. 853-864, 2001.

21. Rasheed, A.; Hornung, H.G.; Federov, A.V. and Malmuth, N.D. Experiments on Passive Hypervelocity Boundary-Layer Control Using an 
Ultrasonically Absorptive Surface. AIAA Journal, vol. 40, no.3, pp. 481-489, March 2002.

22. Moses, Paul L. "NASA Hypersonic Propulsion Flight Demonstrators - Overview, Status, and Future Plans," Presented at the $54^{\text {th }}$ International Astronautical Conference, October 2003.

23. Freeman, Delma C.; Reubush, David E.; McClinton, Charles R.; Rausch, Vincent L. and Crawford, J. Larry. "The NASA Hyper-X Program," Presented at the $48^{\text {th }}$ International Astronautical Conference, October 1997.

24. Mercier, Robert A.; Ronald, T.M.F. "Hypersonic Technology (HyTech) Program Overview," AIAA Paper 98-1566, Presented at the AIAA International Space Planes and Hypersonic Systems and Technologies Conference, April 1998.

25. Anderson, Griffin Y.; McClinton, Charles R. and Weidner, John P. "Scramjet Performance", Scramiet Propulsion, AIAA Progress in Aeronautics and Astronautics, vol. 189, 2000.

26. Hunt, James L.; Pegg, Robert J. and Petley, Dennis H. "Airbreathing Hypersonic VisionOperational-Vehicles Design Matrix," Presented at the 1999 World Aviation Congress and Exposition, San Francisco, California, October 1999.

27. Rogers, R.C.; Shih, A.T.; Tsai, C.Y. and Foelsche, R.O. "Scramjet Tests in a Shock Tunnel at Flight Mach 7, 10 and 15 Conditions," AIAA Paper 2001-3241, AIAA $37^{\text {th }}$ AIAA/ASME/SAE/ASEE Joint Propulsion Conference, July 2001.

28. Foelsche, R.O.; Rogers, R.C.; Tsai, C.Y.; Bakos, R.J. and Shih, A.T. "Hypervelocity Capability of the HYPULSE Sock-Expansion Tube Tunnel for Scramjet Testing," ISSW23-Paper No. 1047, Presented at the $23^{\text {rd }}$ International Symposium on Shock Waves, July 2001.

29. Moses, P.L.; Bouchard, K.A.; Vause, R.F.; Pinckney, S.Z.; Ferlemann, S.M.; Leonard, C.P.; Taylor, L.W.; Robinson, J.S.; Martin, J.G.; Petley, D.H. and Hunt, J.L. "An Airbreathing Launch Vehicle Design with Turbine-Based LowSpeed Propulsion and Dual-Mode Scramjet High-Speed Propulsion," AIAA 99-4948, Presented at the $9^{\text {th }}$ International Aerospace Planes and Hypersonic Systems and Technologies Conference, November 1999.

30. Witte, David W.; Huebner, Lawrence D.; Trexler, Carl A.; Cabell, Karen F. and Andrews, Earl H. $\mathrm{Jr}$. "Propulsion-Airframe Integration test techniques for Hypersonic Airbreathing Configurations at NASA Langley Research Center," AIAA 2003-4406, Presented at the $39^{\text {th }}$
AIAA/ASME/SAE/ASEE Joint Propulsion Conference, July 2003.

31. Huebner, Lawrence D. and Tatum, Kenneth E. "Computational and Experimental Aftbody Flowfields for Hypersonic Airbreathing Configurations with Scramjet Exhaust Flows," AIAA Paper 91-1709, June 1991.

32. Huebner, Lawrence D. and Tatum, Kenneth E. "CFD Code Calibration and Inlet-Fairing Effects on a Three-Dimensional Hypersonic Powered Simulation Model," AIAA Paper 93-3041, July 1993.

33. Tatum, Kenneth E.; Witte, David W.; Monta, William J. and Walters, Robert W. "Analysis of Generic Scramjet External Nozzle Flowfields Employing Simulant Gases," AIAA Paper 905242, December 1990.

34. Engelund, Walter C.; Holland, Scott D.; Cockrell, Charles E. Jr. and Bittner, Robert D. "Aerodynamic Database Development for the Hyper-X Airframe-Integrated Scramjet Propulsion Experiments," Journal of Spacecraft and Rockets, Vol. 38, No. 6, 2001, pp.803-810.

35. Cockrell, Charles E. Jr.; Engelund, Walter C.; Bittner, Robert D.; Jentink, Tom N.; Dilley, Arthur D. and Frendi, Abdelkader. "Integrated Aeropropulsive Computational Fluid Dynamics Methodology for the Hyper-X Flight Experiment," Journal of Spacecraft and Rockets, Vol. 38, No. 6, pp. 836-843.

36. Huebner, Lawrence D.; Rock, Kenneth E.; Witte, David W.; Ruf, Edward G. and Andrews, Earl H. "Hyper-X Engine Testing in the NASA Langley 8-Foot High Temperature Tunnel," AIAA Paper 2000-3605, Presented at the $36^{\text {th }}$ AIAA/ASME/SAE/ASEE Joint Propulsion Conference, July 2000.

37. O'Brien, Timothy F. and Farrell, Daniel J. "Improvements to Beoing SCHNOZ Predictions per Transonic Powered SERN Wind Tunnel Data," AIAA Paper 2003-4409, Presented at the $39^{\text {th }}$ AIAA/ASME/SAE/ASEE Joint Propulsion Conference, July 2003.

38. Meyer, Benjamin. "A Comparison of Computational Results to Transonic Test Data from a Hypersonic Airbreathing Model with Exhaust Simulation," AIAA Paper 2003-4411, Presented at the AIAA 39 AIAA/ASME/SAE/ASEE Joint Propulsion Conference, July 2003.

39. Hanson, John M. "A Plan for Advanced Guidance and Control Technology for $2^{\text {nd }}$ Generation Reusable Launch vehicles," AIAA Paper 2002-4557, Presented at the AIAA Guidance, Navigation and Control Conference, August 2002. 
40. Hanson, John M. and Jones, Robert E. "Advanced Guidance and Control methods for Reusable Launch vehicles: Test Results," AIAA Paper 2002-4561, Presented at the AIAA Guidance, Navigation and Control Conference, August 2002.

41. Shen, Zuojun and Lu, Ping. "On-Board Entry Trajectory Planning Expanded to Sub-Orbital Flight," AIAA Paper 2003-5736, Presented at the AIAA Guidance, Navigation and Control Conference, August 2003.

42. Lu, Ping and Tsai, Bruce. "Closed-loop EndoAtmospheric Ascent Guidance," AIAA Paper 2002-4558, Presented at the AIAA Guidance, Navigation and Control Conference, August 2002.

43. Xin, M., and Balakrishnan, S.N. "A New Method for Suboptimal Control of a Class of Nonlinear Systems," Proceedings of IEEE Conference on Decisions and Control, Las Vegas, NV, Dec 2002.

44. Johnson, E., Calise, A., and Corban, J.E. "A Six Degree-of-Freedom Adaptive Flight Control Architecture for Trajectory Following," AIAA Paper 2002-4776, Presented at the AIAA GN\&C Conference, August 2002.

45. Zhu, J.; Lawrence, D.; Fisher, J.; Shtessel, Y.; Hodel, A.S.; and Lu, P. "Direct Fault Tolerant RLV Attitude Control-A Singular Perturbation Approach," AIAA Paper 2002-4778, Presented at the AIAA GN\&C Conference, August 2002.

46. Hall, Charles E. and Shtessel, Yuri B. "RLV Sliding Mode Control System Using Sliding Mode Observers and Gain Adaptation," AIAA Paper 2003-5437, Presented at the AIAA Guidance, Navigation and Control Conference, August 2003.

47. Jones, Thompas $P$. and Baumann, Ethan. "Evaluation of the X-43A Scramjet Controller Performance by Monte Carlo Technique," AIAA Paper 2003-5192, Presented at the $39^{\text {th }}$ AIAA/ASME/SAE/ASEE Joint Propulsion Conference, July 2003. 
